\title{
Modified formulas for calculation of encephalization: quotient in dogs
}

\author{
Saganuwan Alhaji Saganuwan* (1)
}

\begin{abstract}
Objective: Dogs are a breed of animals that play important roles in security service, companionship, hunting, guard, work and models of research for application in humans. Intelligence is the key factor to success in life, most especially for dogs that are used for security purposes at the airports, seaports, public places, houses, schools and farms. However, it has been reported that there is correlation between intelligence, body weight, height and craniometry in human. In view of this, literatures were searched on body weight, height and body surface areas of ten dogs with intent to determining their comparative level of intelligence using encephalization quotient.

Results: Findings revealed that dogs have relationship of brain allometry with human as proven by encephalization quotient $(E Q)=$ Brain Mass $/ 0.14 \times$ Body weight ${ }^{0.528}$, Brain Mass $/ 0.12 \times$ Body Weight $^{0.66}$

and Brain Mass $(E)=k p \beta$, where $p$ is the body weight; $k=0.14$ and $\beta=0.528$, respectively. Saganuwa's formula yielded better results as compared with the other formulas. Dogs with body surface area (BSA), weight and height similar to that of human are the most intelligent. Doberman pinscher is the most intelligent followed by German shepherd, Labrador retriever, Golden retriever, respectively.
\end{abstract}

Keywords: German shepherd, Allometry, Encephalization quotient, Intelligence

\section{Introduction}

The neural basis of human intelligence in relation to brain weight and head circumference has been identified by computed tomography $(\mathrm{CT})$ and magnetic resonance imaging (MRI). The value range of $0-0.6$ with verbal ability correlating with cerebral volume has been reported for each hemi-sphere in women, and in right handed men accounting for $36 \%$ of the variation in verbal intelligence [1]. Body temperature, food digestion, and phylogeny do not support the scaling of basal metabolic rate (BMR) to 3/4, but support the scaling to $2 / 3$ [2]. Lack of a single exponent model, suggests that there is no universal accepted allometry [3]. Similar objects exhibit isometry, whereas geometrically dissimilar objects exhibit

\footnotetext{
*Correspondence: pharn_saga2006@yahoo.com
}

Department of Veterinary Pharmacology and Toxicology, College

of Veterinary Medicine, Federal University of Agriculture, Benue State,

P.M.B. 2373, Makurdi, Nigeria allometry. Brain weight is an index of intelligence [4], low birth weight is related to intelligence in 3-5-year-old children [5] and variation in brain size is related to intellectual achievement [6]. Numerical comparison of relative brain to body size is called encephalization quotient (EQ) [7]. The EQs for pig and sheep (0.6), giraffe (0.7), Bactrian camel (0.8), Llama and guinea pig (0.9), European cat (1.1), dog (1.2), vicuna (1.4), ring-tailed lemur (1.5), gorilla (1.4-1.7), fox (1.6), Asian elephant (2.3), chimpanzee (2.2.-2.5) and human (7.3-7.7), respectively have been established [7-10].The efficiency of structural organization of brain, could be an important biological basis for intelligence [11]. Metabolic processes and brain size share some relationship with body size across mammals. Hence, lean body mass is the more appropriate scaling parameter for comparing brain size across species [12]. The EQ for dolphin (5.3) and monkey (4.8) suggest that intelligence may depend on the amount of brain nerves, brain's menial chores and brain size [13].

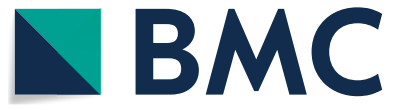

(c) The Author(s) 2021. This article is licensed under a Creative Commons Attribution 4.0 International License, which permits use, sharing, adaptation, distribution and reproduction in any medium or format, as long as you give appropriate credit to the original author(s) and the source, provide a link to the Creative Commons licence, and indicate if changes were made. The images or other third party material in this article are included in the article's Creative Commons licence, unless indicated otherwise in a credit line to the material. If material is not included in the article's Creative Commons licence and your intended use is not permitted by statutory regulation or exceeds the permitted use, you will need to obtain permission directly from the copyright holder. To view a copy of this licence, visit http://creativeco mmons.org/licenses/by/4.0/. The Creative Commons Public Domain Dedication waiver (http://creativecommons.org/publicdomain/ zero/1.0/) applies to the data made available in this article, unless otherwise stated in a credit line to the data. 
Results from evaluations of placental-brain size cannot be applied generally to mammals [14]. The study of human evolution related large brains to increased capacity of expertise not intelligence quotient [15]. Expansion and differentiation of neocortex increase brain size and complex function of the brain [16], carnivores having intermediate values of brain size [17]. Human brain volume, grey matter, white matter, cortical thickness, cortical convolution and neural efficiency are used to measure intelligence [18]. Since different formulas used to calculate EQ provided different values; there is need for modification of the formulas with a view to providing formula that would provide efficient EQ.

\section{Main text}

\section{Materials and methods}

All the mathematical equations used in the present study have relationship between brain mass and body height of man. The formulas are presented as follow: Brain Mass $=920 \mathrm{~g}( \pm 113)+2.70( \pm 0.65) \times$ body height of man; Brain Mass $=748 \mathrm{~g}( \pm 104)+3.10( \pm 0.64) \times$ body height of woman [19]. Animal EQ is calculated using the formula,

$\frac{\text { Brain Mass }}{2 / 3}$ [17], modified as $\left(\frac{\text { Brain Mass }}{0.14 \times \text { Bodyweight }{ }^{0.528}}\right)$ and used for the present study. Majority of animals are assumed to have an EQ of 1 . Therefore a value greater than 1, may suggest higher than average intelligence [7]. However, percent body fat $(\%$ bf $)=0.339+2.942$ $(\operatorname{logWT})[12]$, where WT is body weight, should be considered when the dogs are either obese or over weight. The formula for linking hominid skull volume to brain volume is $\log _{10}(B)=3.015+0.986 \log _{10}(C)$, where $B$ (total brain size in $\mathrm{mm}^{3}$ ) and $\mathrm{C}$ (internal cranial capacity in cubic millimeter) is expressed as $y=0.39 x^{0.27}$, where 0.39 (integral constant), $\mathrm{X}$ (body weight mean) and 0.27 (allometric exponent).These parameters are potentially associated with intraspecies ratio of body weight and body weight means [20]. Also brain weight is calculated as $E=k \rho \beta$ where $E$ is the brain weight, $\rho$ is the body weight, $\mathrm{k}$ and $\beta$ are determined from $\log -\log$ plot of brain weight to body weight. $\log k$ is the $\log E$ intercept and $\beta$ is the slope [17]. Whereas $\mathrm{k}=0.18$ and $\beta=0.66$ respectively [21]. However $\mathrm{k}=0.16$ and $\beta=0.67$ have also been reported [17]. The intelligence of dogs was classified according to Coren [22] in decreasing order as follows: Border collie, Standard Poodle, German shepherd, and Golden retriever, Doberman pinscher, Shetland, Labrador retriever, Papillion, Rottweiler and Australian Cattle Dog used in the present study. Their body weight, body surface area, height, $\mathrm{k}=0.14$ and $\beta=0.528$ were applied as reported by Saganuwan [23]. Total brain volume and age of the dogs were calculated using the formulas $\mathrm{TBV}=182.3+0.7 \times$ Cranial Capacity and $\mathrm{TBV}=396.5 \mathrm{X}$ Age $+0.7 \times \mathrm{CC}$ respectively [24]. Oneyear mature-senior dog is equivalent to 13.125 year human. Also the age of dog based on epigenetics is calculated thus: Dog Age $=A \times \ln ($ Human Age $)+B$, whereas $\mathrm{A}$ and $\mathrm{B}$ are coefficients estimated by bootstrapping an equal number of both humans and dogs [25].

\section{Results}

The body weight, brain weight, body surface area, height and encephalization quotient of the ten dogs are presented in Table 1. The calculated brain weights for all the dogs using von Bronin's formula were higher than the weights yielded by Jerison's and Saganuwan's formulas. Saganuwan's formula yielded highest EQ for Border collie (2.3), Standard Poodle (2.2), German Sheperd (3.1), Golden Retriever (2.8), Doberman pinscher (3.1), Labrador retriever (2.9) and Australian Cattle Dog (2.7) as compared to the other formulas. However von Bronin's formula yielded highest EQ for Rottweiler (2.5) as Jerison's formula yielded highest EQ for Shetland Sheep Dog (1.4) and Papilon (1.2). German Shepherd had highest total brain size (TBS)/internal cranial capacity (ICC) ratio (1.4) followed by Labrador Retriever, Doberman pinscher, Golden retriever (1.3), Border collie, Standard Poodle, Papilon (1.2) and Shetland Sheep Dog (1.1), respectively. The calculated ICC parameter showed that Rottweiler and German shepherd scored highest, 11 (Table 1).

\section{Discussion}

The intelligence quotient of 1.0-3.1 reported for the dogs used in the present study disagrees with the report indicating that, the EQ for dogs was 1.2 [7-10]. EQs calculated from Saganuwan's formula developed for both dog and human, shows that Doberman pinscher has the highest $\mathrm{EQ}$, hence, considered the most intelligent followed by German shepherd, Labrador retriever, Golden retriever, Australian Cattle Dog, Rottweiler, Border collie, Standard Poodle, Shetland Sheep Dog and Papilon, respectively. The EQ $>1$ indicates larger brain, EQ $=1$ (average) and smaller $(E Q<1)$, respectively [26]. Each of the formulas used to calculate EQ yields different values, but the formula developed by Saganuwan may be more reliable. The TBS/ICC value higher than 1 and EQ value of 1.0-3.1 show that even Papilon is intelligent. Intelligence, learning, awareness and the welfare are closely related. Self-aware animals should be able to deduce mental states of other animals [27]. This is classified as a form of complex learning [28], signifying that level of intelligence is directly proportional to level of awareness [7]. However, awareness is a state that comprises conscious thought and unanxious responses [29]. Learning and 


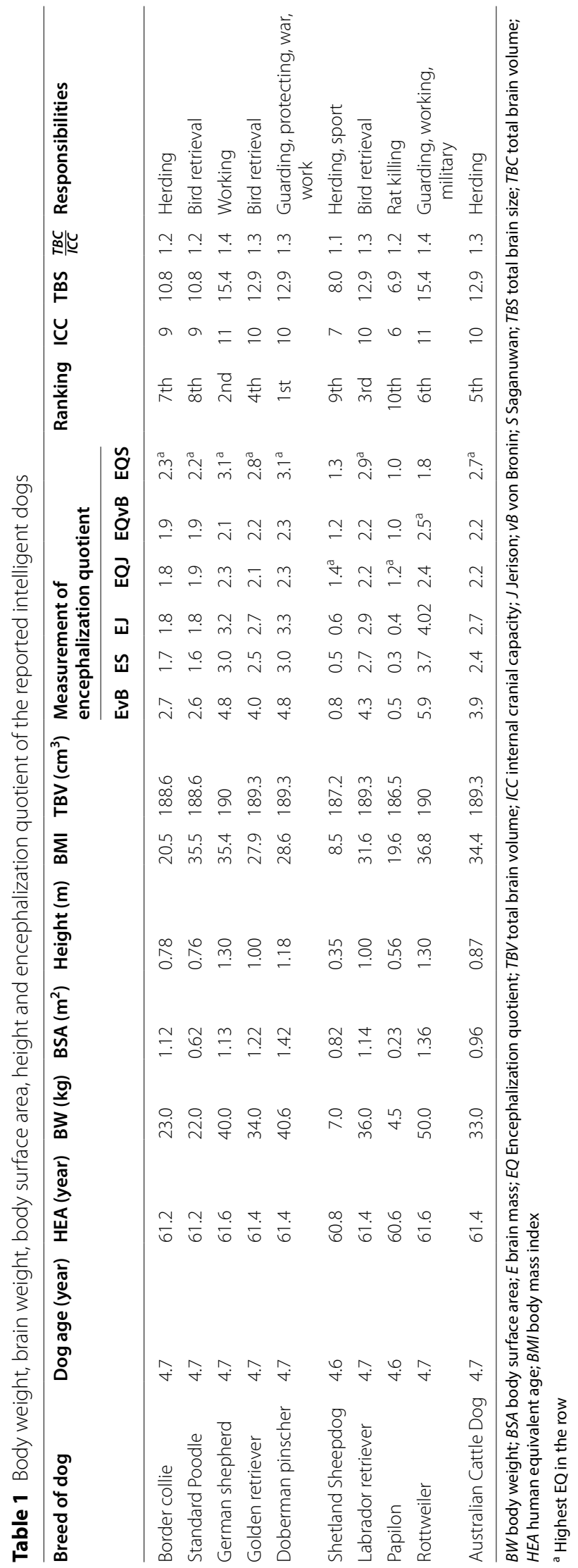


awareness are connected with environment, past experiences, relationships between old and new information, and action to produce a positive outcome [30]. Acquisition of neutral information with no immediate effects on behavior is known as latency [31], seen between a naive and experienced animal [7]. However dog's intelligence is of three components; instinctive intelligence, adaptive intelligence as well as working and obedience intelligence [22].Therefore the intelligence of dogs may be classified according to their functions as working (e.g., Doberman pinscher, German shepherd, Border collie), hunting (Labrador retriever, Golden retriever), companion (Standard Poodle) and toying (Papilon) intelligence, respectively [23]. Nutrition, genetics, environment, diseased condition inter alia, may affect EQ. However, study on evolution of encephalization quotient revealed that carnivore and other mammals showed abrupt increase in median log-encephalization quotients, indicating higher brain volume relative to body mass, at the end-midcene, but gradual increases in the variance of log EQs. By akaike information criterion, evolution of camid encephalization proposed plesiomorphic and apomorphic allometries [32]. Hence increased camid encephalization coincides with reorganization of the brain, which reflects complex social behaviour overtime [33]. The reported value of EQ (0.4) for African grass cutter [34] shows that the animal's level of intelligence is quite low as compared to that of dog, which may allow easy predation by dog on the grass cutter. In another development, the therapeutic implication of EQ $>1$ is that, central nervous system acting drug, which has fulfilled the condition of cerebrospinal fluid (CSF) penetration, may be accumulated more in the brain tissues of dogs with higher EQ. This is because the larger the volume of the brain tissue, the higher the apparent volume of distribution of the drug. Relative reduction in brain size could increase the chance of obesity [35], and obese dog may be relatively dull. Hence fat could affect calculated value of encephalization quotient [36]. The brain weight could be an indicator of cognitive capacity development [37]. Therefore cognition is related to neurobiology and ecology [38]. More encephalized species have larger promontorial canal relative to transverse foramina, thereby increasing endocranial volume [39]. DNA methylation is a diagnostic tool for physiological aging in dogs [40], as observed in the present study, comprising dogs of 4.6 and 4.7 years of age, that may not be vulnerable to hippocampal atrophy, which could cause cognitive dysfunction in dogs of age $\geq 9$ years. Hippocampal atrophy is a neurodegenerative disease in dogs similar to Alzheimer's disease of human [41]. Dogs that have higher body weight relative to height, such as Doberman pinscher, German shepherd, Labrador retriever and Golden retriever rated first to fourth intelligent agree with the report, indicating that there is strong association between physical attractiveness and intelligence [42-44]. The difference in intelligence of the dogs in the present context may be due to significant anatomical variation among the breeds [45], suggesting that dogs have large number of neurons in the cerebral cortex [46]. Hence they are voice-sensitive [47]. Also temporal cortex activation is highly functional in perception of human faces by dogs [48], which is dependent on colour vision, sensitivity to light, visual acuity and cognition capacity [49]. Therefore animality is a threshold between human being and other animals [50].

\section{Conclusion}

Body weight, height and body surface area can be used to estimate encephalization qotient of dogs, which can vary according to formulas, nutrition, environment and diseased conditions. The calculated parameters showed that Doberman pinscher is the most intelligent followed by German shepherd, Labrador retriever, Golden retriever, Australian Cattle Dog, Rottweiler, Border collie, Standard Poodle, Shetland Sheep Dog and Papilon, respectively.

\section{Limitations}

The calculations were based on different formulas generated for different or similar purposes in dog and human. Intelligence in dogs and human is used for different assignments even within canine species. More so difference in physiology, anatomy and biochemistry count for differences in the calculated values.

\section{Abbreviations \\ P: Body weight; K: 0.14; $\beta$ : 0.528; EQ: Encephalization quotient. \\ Acknowledgements \\ The author sincerely thanks Mr. Kehinde Ola Emmanuel of Open University Abuja for typing the work.}

Authors' contributions

SAS designed, carried out the study, analyzed data, wrote and proof read the manuscript. The author read and approved the final manuscript.

Funding

Not applicable.

Availability of data and materials

All data generated or analyzed are included in this published article.

\section{Declarations}

Ethics approval and consent to participate

Not applicable, because neither human nor animal was used for the study.

\section{Consent to publish}

Not applicable.

Competing interests

The author declares that he has no competing interests. 
Received: 28 December 2020 Accepted: 26 May 2021

Published online: 03 June 2021

\section{References}

1. Witelson SF, Beresh H, Kegar DL. Intelligence and brain size in 100 Postmortan brains: Sex, lateralization and age factors. Brain. 2006;129:386-98.

2. White $C R$, Seymow RS. Mammalian Basal metabolic rate is proportional to body mass. PNAS. 2003;100(7):4046-9.

3. Witelson SF, Beresh $\mathrm{H}$, Kigar DL. Intelligence and brain size in 100 postmortem brains: sex, lateralization and age factors. Brain. 2006;129(2):386-98.

4. Reiling J. Brain weight as index of intelligence. JAMA. 1999;282(7):1-4.

5. Lee $\mathrm{S}$, Paik A, Min A, Ahn DH. The relationship between intelligence and birth weight among 3-5 years old children with low birth weight. JAACAP. 2016;55(10):8136.

6. Rushton JP, Anknay CD. The evolution of brain size and intelligence. In: Platek SM, Keenan JP, Shackel-Fords TK, editors. Evolutionary Congrutive Neuroscience. Cambridge: MIT Press; 2021. p. 121-61.

7. Tansley C. What do we mean by the term 'talent" in talent management Indus Commerc Train. 2011;43(5):266-74

8. Mace GM, Harvey PH, Chitton-Brock TH. Is brain size an ecological variable? Trend Neurosci. 1980:3:193-6.

9. Roth G, Dicke U. Evolution of the brain and intelligence. Trend Cognit Sci. 2005;9:250-7.

10. Shoshani J, Kupsky WJ, Marchant GH. Elephant brain: part 1: gross morphology, functions, comparative anatomy and evolution. Brain Res Bull. 2006;70:174-57.

11. Li Y, Liu Y, Li J, Qin W, Li K, Yu C, Jiang T. Brain anatomical network and intelligence. Plus ONE. 2009;5(5):1-17.

12. Schoeneman PT. Brain size scaling and body composition in mammals. Brain Behav Evol. 2004:63:47-60.

13. Fox D. The limits of intelligence. Sci Am. 2011;305:37-43.

14. Weisbecker $\mathrm{V}$, Goswani A. Brain size, life history and metabolism at the marsupial/placental dichotomy. PNAS. 2010;107(37):16216-21.

15. Skoyles JR. Human evolution expanded brains to increase expertise capacity, not 1Q. Psycholoquy. 2017;10:1-14.

16. DeFelipe J. The evolution of the brain, the human native of cortical circuits and intellectual creativity. Front Neurosci. 2011:5:1-17.

17. Jerison HJ. Brain to body ratio and the evolution of intelligence. Science. 1955:121(3144):447-9.

18. Pietsechnig J, Penke L, Wicherts JM, Zeiler M, Voracek M. Meta-analysis of associations between human brain volume and intelligence differences: how strong are they and what they mean? Neurosci Behav Rev. 2015:57:411-32.

19. Ankney CD. Sex differences in relative brain size: the mismeasure of woman too? Intelligence. 1992;16:329-36.

20. Bronson RT. Brain weight-body weight scaling in breeds of dogs cats. Brain Behav Evol. 1979;16(3):227-36.

21. von Bronin G. Brain-weight and body-weight of mammals. J Gen Psychol. 1937;16(2):379-89.

22. Coren S. The intelligence of Dogs: A guide to the thoughts, emotions, and inner lives of our canine companions. New York: Free Press; 2006. p. 299.

23. Saganuwan SA. Derivation of a unique body surface area (bsa) formula for calculation of relatively safe doses of dog and human anticancer drugs. J Cancer Sci Ther. 2017;9(10):690-704.

24. Ricard AS. Equations about brain volume, cranial capacity and age. Surg Radiol Anat. 2010;32(10):989-95.

25. Wang T, Ma J, Hogan AN, Fong S, Licon K, Tsui B, Kreiberg JF, Adams PD, Carvunis A-R, Banasch DL, Ostrander EA, Ideker T. Quantitative translation of dog-to-human aging by conserved remodeling of the DNA methylome. Cell Syst. 2020;11:1-10.

26. Mnervini S, Pirone AA, Graic JM, Dessantis SC. Brain mass and encephalization quotient in the domestic industrial pig (Sus scrofa). Plos ONE. 2016;11(6):e0157378.

27. Gallup GG Jr. Self-awareness and the evolution of social intelligence. Behav Process. 1998;42:239-47.

28. Emery NJ, Clayton SN. The mentality of crows; convergent evolution of intelligence in corvids and apes. Science. 2004;306:1903-7.
29. Sommerville BA, Broom DM. Olfactory awareness. Appl Anim Behav. 1998;57:269-86.

30. Broom DM, Sena H, Moynihan KL. Pigs learn what a mirror image represents and use it to obtain information. Anim Behav. 2009;78:1037-43.

31. Stouffer EM. The entorrhinal cortex, but not the dorsal hippocampus is necessary for single are latent learning. Hippocampus. 2010;20:1061-71.

32. Akaike $\mathrm{H}$. Information theory and an extension of the maximum likelihood principle. In: Proceedings of the 2 nd internternational symposium on information theory. Akademia Kiado: Budapest; 1973. p. 267-81.

33. Finarelli JA. Hierarchy and the reconstruction of evolutionary trends: evidence for constraints on the evolution of body size in in terrestrial caniform carnivorans (Mammalia). Paleobiology. 2008;34(4):553-62.

34. Baynet O, Dzada T. Quantitative biometry of body and brain in the grass cutter (Thryonomys swinderianus) and Afriacan giant rat (Cricetomys gambianus): encephalization quotient implication. Res Neuro Sci. 2014;3(1):1-6.

35. Rishniv M, Dewey CW. Little brainiacs and big dummies: are we selecting for stupid, stout or smelling dog? Open Vet J. 2021;11(1):107-11.

36. Cairo O. External measure of cognition. Front Human Neurosci. 2011:5(108):1-9.

37. Perepelkina OV, Tarasova AY, Ogienko NA, Lilp IG, Poletaeva II. Brain weight and cognitive abilities of laboratory mice. Biol Bull Rev. 2020;10:91-101.

38. Logan CJ, Avin S, Boogert N, Buskell A, Cross FR, Currie A, Jelbert S, Lukas D, Mares R, Navarret AF, Shigeno S, Montgomery SH. Beyond brain size. Comp Cogn Behav. 2018. https://doi.org/10.1101/145334.

39. Boyer DM, Harrington AR. Scaling of bony canals for encephalic vessels in euarchontans: implications for the role of the vertebral artery and brain metabolism. J Human Evol. 2018;114:85-101.

40. Dewey CW, Rishniv M, Johnson PJ, Platt S, Robinson K, Sackman J, O'Donnell M. Canine cognitive dysfunction patients have reduced total hippocampal volume compared with aging control dogs: a comparative magnetic resonance imaging study. Open Vet J. 2020;10(4):438-42.

41. Kanazawa S. Intelligence and physical attractiveness. Intelligence. 2011;39:7-14.

42. Harris MA, Brett CE, Deary IJ, Starr JM. Association among height, body mass index and intelligence from age 11 to age 78 years. BMC Geriatr. 2016;16(167):1-10

43. Schmidt MJ, Amort KH, Failing K, KIniger M, Kramer M, Ondreka N. Comparison of the endocranial-and Covalier King Charles spaniels in relation to their body weight. Act Vet Scand. 2014;56(30):1-9.

44. Hecht EE, Smaers JB, Dunn WJ, Kent W, Preuss TM, Gutman DA. Significant neuroanatomical variation among domestic dog breeds. J Neurosci. 2019. https://doi.org/10.1523/JNEUROSCl.0303-19.2019.

45. Jardin-Messeder D, Lambert K, Noctor S, Pestana FM, de Castro Leal ME, Bertelsen MF, Alagaili AN, Mohammed OB, Manger PR, Herculano-Houze $S$. Dogs have the most neurons, not the largest brain: trade-off between body mass and number of neurons in the cerebral cortex of large carnivoran species. Front Neuroanat. 2017:11(118):1-18.

46. Herculano-Houzel S. The remarkable, yet not extraordinary human brain as scaled-up primate brain and its associated cost. PNAS. 2012;109(1):10661-8.

47. Andics A, Gacsi M, Farago T, Kis A. Voice-sensitive regions in the dog and human brain are revealed by comparative fMRI. Curr Biol. 2014;24:574-8.

48. Cuaya LV, Hernandez-Perez R, Concha L. Our faces in the dog's brain: functional imaging reveals temporal cortex activation during perception of human faces. Plos ONE. 2016;11(3):1-13.

49. Boysiere S-E, Chouinard PA, Howell TJ, Bennett PC. What do dogs (Canis familiaris) see? a review of vision in dogs and implications for cognition research. Psychon Bull Rev. 2018;25:1798-813.

50. Liljefors M. In between the human and the animal: subjectivity and authority in Ann-Sofi Siden's Queen of Mud project. Konsthistor Tidskr. 2019;79(4):185-99.

\section{Publisher's Note}

Springer Nature remains neutral with regard to jurisdictional claims in published maps and institutional affiliations. 